\title{
Miten tuottava lehmä käyttää aikansa? - Tutkimus lehmien ajankäytöstä automaattilypsytiloilla
}

\author{
Petri Koivisto ${ }^{2}$, Heli Wahlroos ${ }^{1}$, Jouni Pitkäranta ${ }^{3}$, Pirjo Suhonen ${ }^{1}$ \\ ${ }^{1}$ Savonia-ammattikorkeakoulu, PL 72, 74101 Iisalmi, etunimi.sukunimi@savonia.fi \\ ${ }^{2}$ ProAgria Oulu, etunimi.sukunimi@proagria.fi \\ ${ }^{3}$ Arkkitehtitoimisto Jouni Pitkäranta Oy, jouni.pitkaranta@netikka.fi
}

Maidontuotannon kannattavuuden tehostaminen vaatii koko tuotospotentiaalin tarkastelua. Ruokintaan ja jalostukseen hukataan helposti resursseja, jos olosuhteet eivät ole kunnossa. Tuotoksen parantamiseksi on tärkeä tietää, kuinka lehmä käyttäytyy ja kuinka eri tuotostason lehmät käyttävät aikansa. Mikä saa lehmän tuottamaan enemmän maitoa? Automaattilypsy myös antaa lehmille mahdollisuuden rytmittää päivänsä, sillä ihminen ei puutu lehmän ajan käyttöön tietoisesti. Tutkimuksissa tuotostason kasvu on vähentänyt lehmien makuuaikaa, mutta joidenkin asiantuntijoiden mukaan makuuajan lisäys lisää maitotuotosta. Tässä tutkimuksessa verrataan kahdella tilalla eri tuotostasoisen lehmän ajankäyttöä. Tutkimuksen tavoitteena oli löytää lehmien ajankäytöstä tuotoseroja selittäviä tekijöitä.

Tutkimusta varten kahdelta automaattilypsytilalta valittiin tutkimuskohteiksi kolme lehmää kummaltakin. Lehmät olivat perimältään ja laktaatiovaiheeltaan samantasoisia, mutta tuotostasoltaan erilaisia. Perimää arvioitiin käyttämällä pohjoismaista kokonaisjalostusarvoa vertailutyökaluna. Lehmien käyttäytymistä seurattiin kolme vuorokauden mittaista jaksoa. Seurannassa käytettiin time lapse -videokameroita, jotka nopeuttivat tapahtumat 20 kertaa reaaliaikaa nopeammiksi. Videoilta seurattiin sekä ennalta määriteltyjä toimintoja että yllättäviä tapahtumia. Kaikki yli yhden minuutin mittaiset toiminnot kirjattiin. Seurattavia toimintoja olivat lypsy, syöminen, makaaminen, seisoskelu niin käytävällä kuin parressa, odottelu lypsyrobotille, juominen ja karjaharjan käyttö. Videolta tehtyjen havaintojen perusteella laskettiin lehmien päivittäinen ajankäyttö. Lisäksi huomioitiin toimintajaksojen lukumäärä ja yksittäisten jaksojen kesto. Lypsyrobotilta kerättiin lypsytiedot, joista laskettiin tutkimuspäivien maitotuotokset. Lisäksi kirjattiin havaintoja lehmien sosiaalista asemasta ja ruokinnan vaikutuksesta. Keskimäärin puolet lehmien ajasta kului makuulla. Neljänneksen vuorokaudesta ne käyttivät syöntiin ja lähes saman ajan seisoskeluun. Loppu aika jäi lypsyyn, juomiseen ja karjaharjan käyttöön. Ensimmäisellä tilalla maitotuotoksen kasvaessa lehmän makuulla viettämä aika vähentyi ja samalla seisoskelu niin parressa kuin käytävällä lisääntyi. Toisella tilalla yhtä suoraviivaista tulosta ei saatu. Makuuaika ei kuitenkaan lisääntynyt tuotoksen kasvaessa. Molemmilla tiloilta saatiin viitteitä siitä, että sosiaalinen asema jossain määrin vaikuttaa tuotostasoon. Seisoskeluajan lisääntyminen ei välttämättä kuitenkaan ole suoraa tuotosta lisäävä tekijä vaan se voi kertoa lehmän kyvystä sopeuttaa toimintaansa epäsuotuisiin olosuhteisiin. Paljolla seisoskelulla on todettu olevan yhteys lisääntyneisiin jalkaongelmiin, joten tilojen välisiä tuloksia verratessa herää kysymys, kärsivätkö korkeatuottoisimmat lehmät huonoissa olosuhteissa? Lehmien tuotokseen ja käyttäytymiseen vaikuttaa niin monta asiaa, että yksiselitteistä vastausta ei varmasti saada koskaan.

Asiasanat: aikabudjetti, maitotuotos 


\section{Johdanto}

Lypsykarjataloudessa on olennaista tuottaa mahdollisimman paljon maitoa mahdollisimman pienin kustannuksin. Tuotetun maidon määrään vaikuttavat monet tekijät. Ruokinta ja perintötekijät ovat tärkeitä, mutta myös olosuhteet vaikuttavat lehmien tuotokseen. Joidenkin arvioiden mukaan ainoastaan puolet tilojen välisistä tuotoseroista selittyy ruokinnalla. Hyvä ruokinta ja pitkäjänteinen jalostus eivät auta tuotoksen kasvattamisessa, jos olosuhteet eivät ole kunnossa (Sarjokari 2015).

Maitotilojen tilanne on vaikeutunut tuottajahintojen laskiessa. Tämän vuoksi tiloilla on entistä enemmän huomioitava se, miten maitotuotos saadaan optimoitua ja kannattavuus pysymään hyvänä. Olosuhteiden parantaminen ei välttämättä tarvitse suuria investointeja. Tärkeintä on ymmärtää mitä lehmä tarvitsee tuottaakseen mahdollisimman paljon maitoa. Kun ymmärretään lehmien tarpeet, voidaan tuotantopanoksista saada kaikki potentiaali irti. Toisaalta suurempia investointeja tehtäessä on hyvä ymmärtää olosuhdevalintojen vaikutukset. Lehmien vastetta vallitseviin olosuhteisiin voidaan ymmärtää ainoastaan tutkimalla niiden käyttäytymistä (Hulsen 2014).

Automaattilypsy mahdollistaa jokaiselle lehmälle yksilöllisen lypsyrytmin, jolloin lypsyvälit voi- vat olla melko lyhyitä. Erityisesti lehmillä, joilla lypsytiheys on suuri, se voi myös aiheuttaa ongelmia, sillä lehmä joutuu todennäköisesti käymään yöllä lypsyllä, mikä sekoittaa lehmän yölepoa ja normaalia käyttäytymistä. (Helmreich ym. 2014) Lypsyjen jakautuminen koko- päivän ajalle rikkoo joka tapauksessa lehmien luonnollista laumakäyttäytymistä (Winter ja Hillerton 1995). Siitä huolimatta automaattilypsy lisää maitotuotosta, koska se lisää lehmien lypsykertoja päivässä keskimäärin 2.5-2.7 kertaan (Hulsen 2014). Lehmien mahdollisuus, vaikkakin tietyin rajoittein, rytmittää omaa lypsyllä käyntiään on mielenkiintoinen elementti tässä opinnäytetyössä.

Ajankäytön ja tuotoksen välisistä yhteyksistä on olemassa erilaista tietoa erityisesti makuuajan osalta. Sekä parsi- että pihattonavetoissa tehdyissä tutkimuksissa on todettu, että enemmän tuottavat lehmät makaavat vähemmän kuin vähemmän tuottavat lehmät (Deming ym. 2012, Norring ym. 2012). Joidenkin asiantuntijoiden mukaan makuuajan ja maito- tuotoksen välillä on taas positiivinen yhteys (Hulsen ja Rodenburg 2010, Grant 2011). Tietyissä olosuhteissa makuuajan lisääntyminen voi lisätä tuotosta, vaikka tutkimukset osoittavatkin enemmän tuottavien makaavan vähemmän. Nigel Cookin (2016) mukaan makuuajan ja maitotuotoksen välillä ei ole yhteyttä. Cookilla on käytössä laaja aineisto eri tiloilta, jolloin myös erilaiset olosuhteet voivat vaikuttaa tulokseen.

Tässä työssä tutkitaan eri tuotostasoisten lehmien ajankäyttöä. Tavoitteena on löytää eroavai- suuksia tuotostasoltaan erilaisten, mutta perimältään ja laktaatiovaiheeltaan samanlaisten, lehmien ajankäytöstä automaattilypsyä käyttävillä tiloilla ja lisätä ymmärrystä lehmien käyttäytymisen ja maitotuotoksen välisestä yhteydestä. Lisäksi pohditaan olosuhteiden vaikutuksia käyttäytymiseen jo olemassa olevan tiedon pohjalta.

\section{Materiaalit ja menetelmät}

Tutkimuksessa käytetty aineisto kerättiin kahdelta pohjoissavolaiselta automaattilypsytilalta käyttämällä time lapse -kameroita (Kuva 1). Time lapse -kuvaus nopeuttaa tapahtumat, mutta samalla myös saatavan videon koko pysyy kohtuullisena. Videoilta seurattiin kolmea lehmää kummaltakin tilalta strukturoidun havainnoinnin avulla. Ennen videoiden katsomista oli mietitty asioita, joita videolta halutaan nähdä, mutta myös ennalta arvaamattomat asiat kirjattiin ylös. Molemmilla tiloilla kuvattiin kolme vuorokauden mittaista jaksoa. Lypsyroboteilta kerättiin lypsytiedot. 


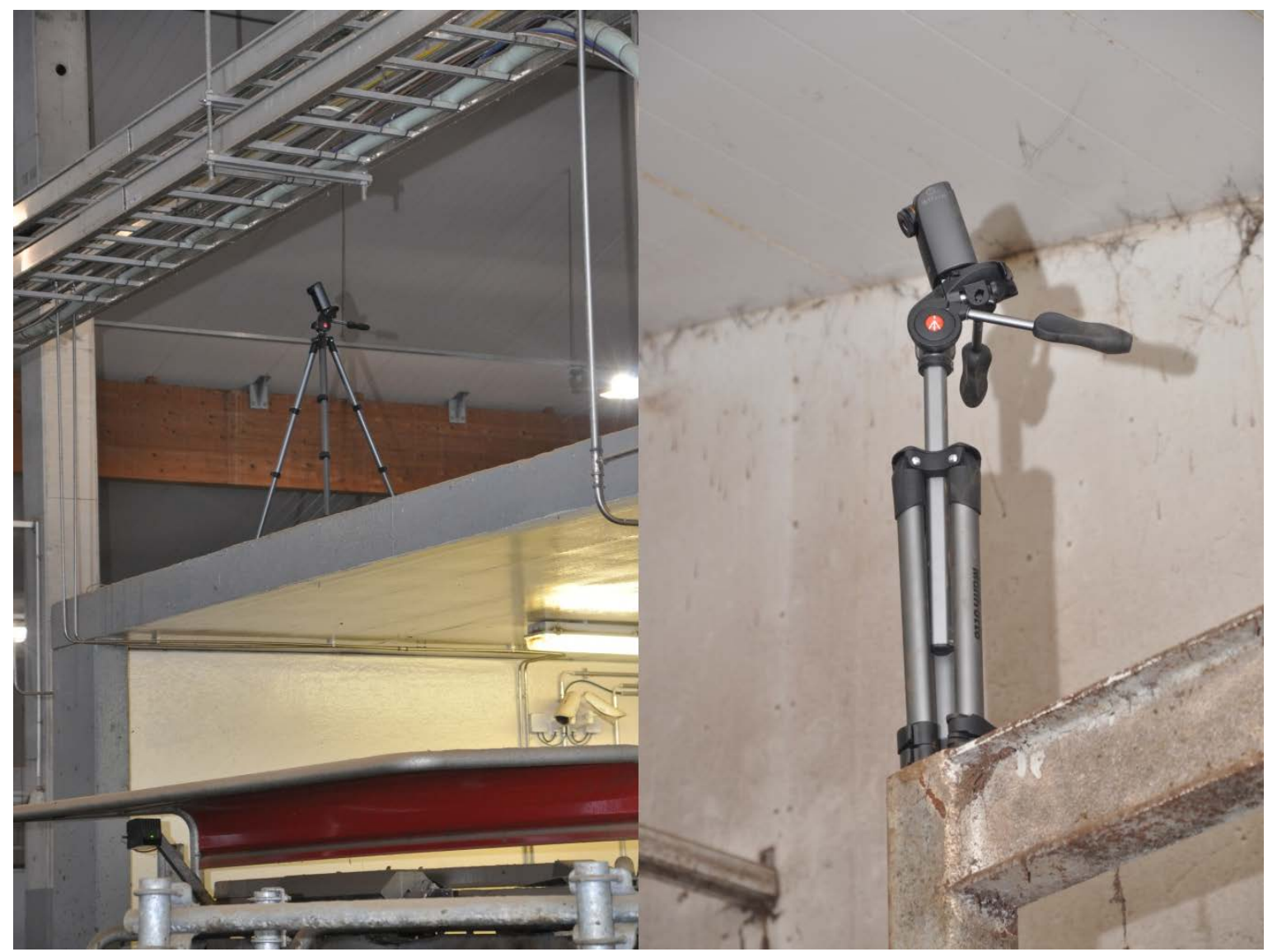

Kuva 1. Kamera robottikopin katolla ja tolpassa ruokintapöydän päässä (Koivisto 2016)

Tilat valittiin omien kontaktien kautta. Molemmilla tiloilla oli käytössä Lelyn lypsyrobotit vapaalla eläinliikenteellä. Lisäksi navettojen pohjaratkaisut olivat riittävän yksinkertaisia, jotta seuranta voitiin tehdä kahdella kameralla. Navettojen pohjaratkaisut olivat saman tyyppisiä: parret kolmessa rivissä ja ruokintapöytäsivulla. Tilojen välillä oli eroja ruokintaesteessä ja ruokintajärjestelmässä. Tilalla A oli automaattinen seosrehuruokinta ja tilalla B traktorikäyttöinen seosrehuruokinta.

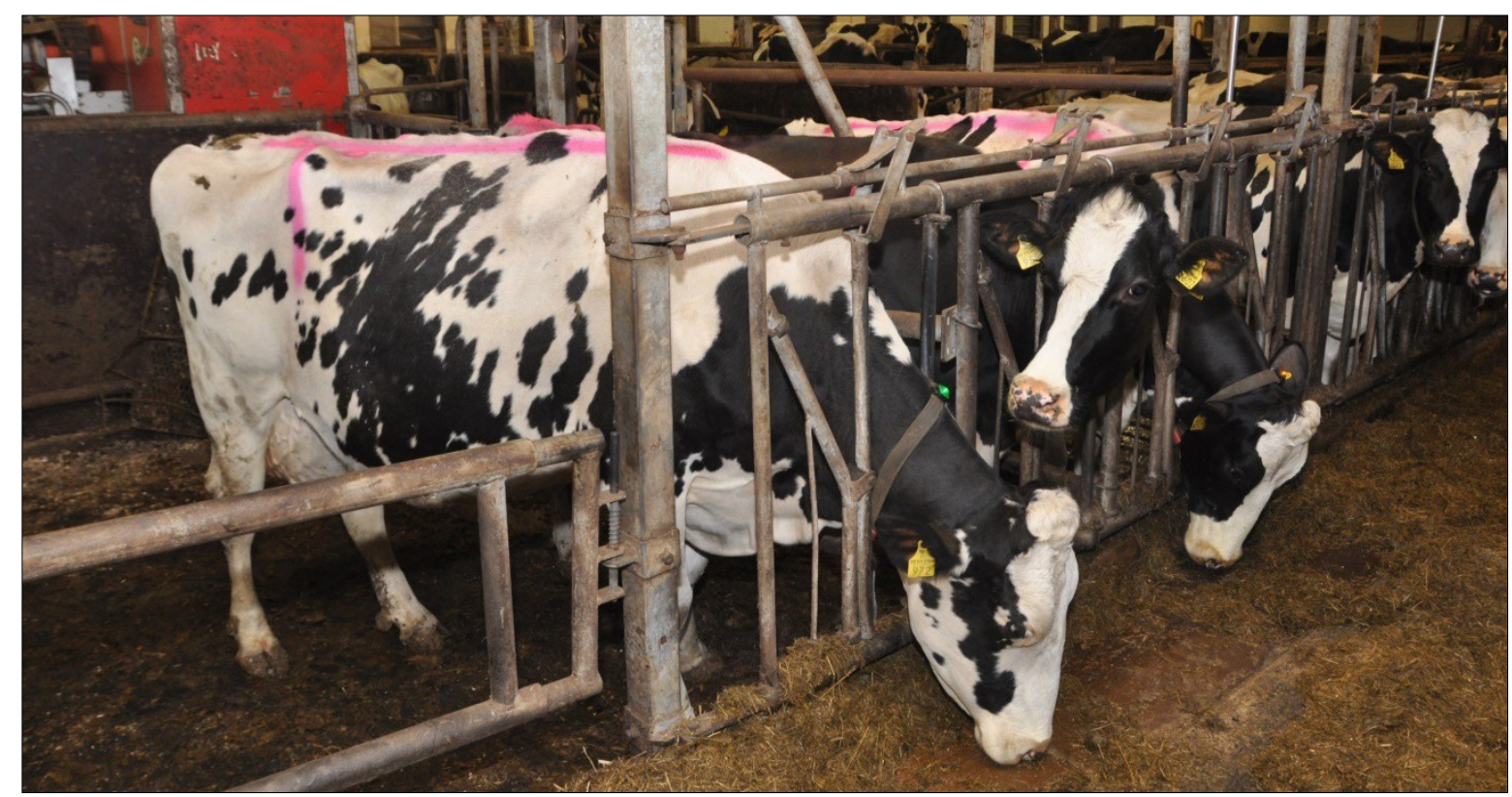

Kuva 2. Tutkimusta varten merkityt lehmät tilalla A (Koivisto 2016) 
Tutkimuksessa seurattavaksi lehmiksi valittiin molemmilta tiloilta kolme lehmää (Kuva 2), jotka olivat iältään, laktaatiovaiheeltaan ja jalostusarvoltaan mahdollisimman samanlaisia, mutta tuotostasossa oli eroja. Tilalla A kaikki lehmät olivat viisi kertaa poikineita. Tilalla B kaksi lehmistä oli poikinut kolme kertaa ja yksi neljä kertaa. Lehmät nimettiin tuotostason mukaan siten, että tilan A lehmistä eniten tuottava oli A1 ja vähiten tuottava A3. Tilalla B lehmät nimettiin samalla logiikalla.

\section{Tulokset}

Lehmät käyttivät molemmilla tiloilla suurimman osan päivästään makaamiseen, johon kului noin puolet vuorokaudesta (Kuva 3). Seuraavaksi eniten aikaa kului syöntiin ja seisoskeluun eri paikoissa: parressa tai käytävällä. Juomiseen ja karjaharjan käyttöön kului keskimäärin alle puoli tuntia.
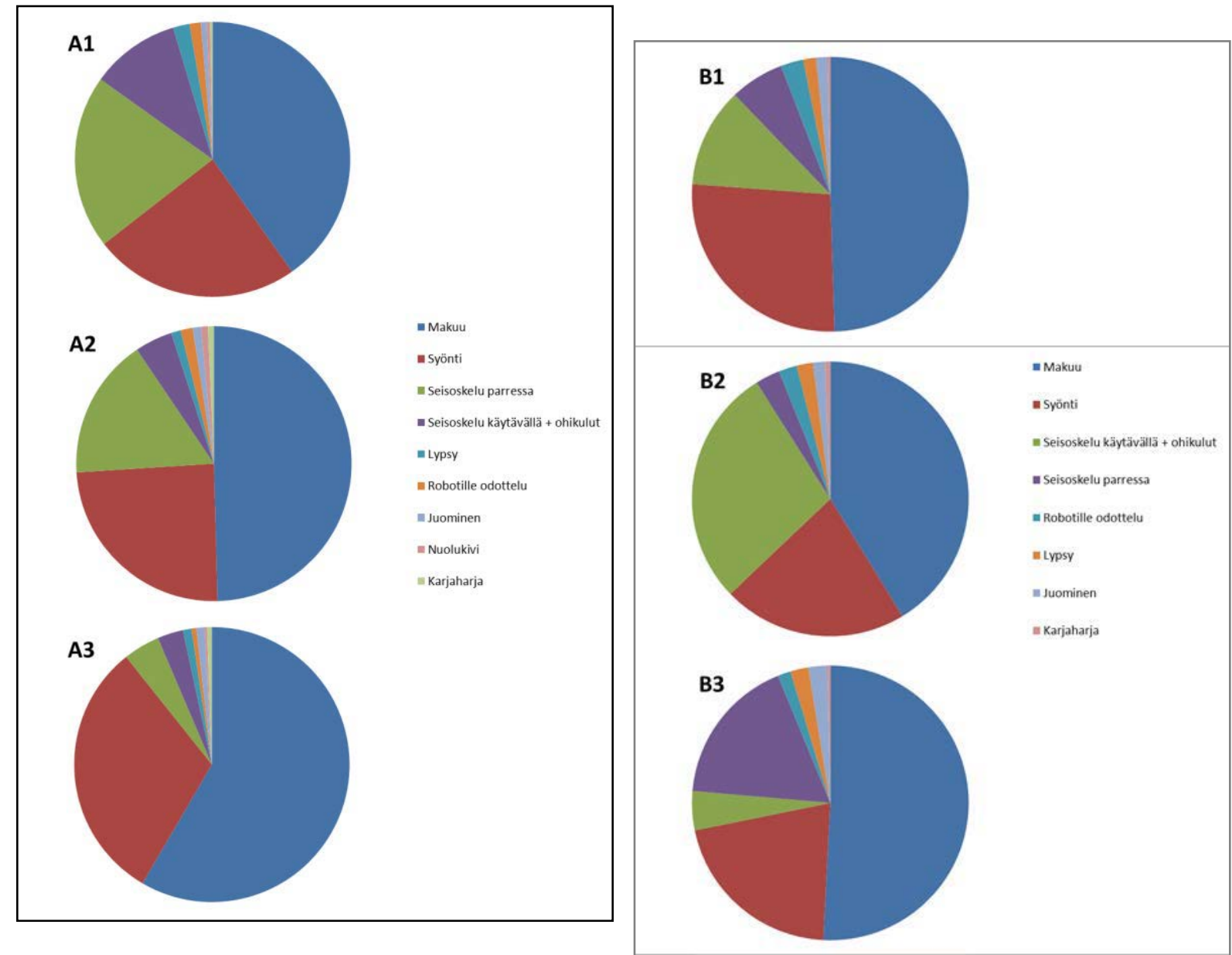

Kuva 3. Lehmien keskimääräiset aikabudjetit vuorokaudessa. Vasemmalla tilan A lehmät ja oikealla tilan B lehmät.

\section{Tila A}

Lehmien päiväkohtaiset energiakorjatut maitomäärät vaihtelivat tilalla A 34.1 kg:sta 43.1 kg:aan. Tilalla A-lehmien makaamiseen käyttämä aika väheni tuotoksen kasvaessa (Kuva 4). Samalla lehmien parressa ja käytävällä seisoskeluun käyttämä aika lisääntyi tuotoksen kasvaessa. Tuotostason kasvaessa yksittäisten makuujaksojen keskimääräinen aika kasvoi ja jaksojen lukumäärä väheni. Syöntiin käytetty aika vähentyi hieman tuotoksen kasvaessa. 


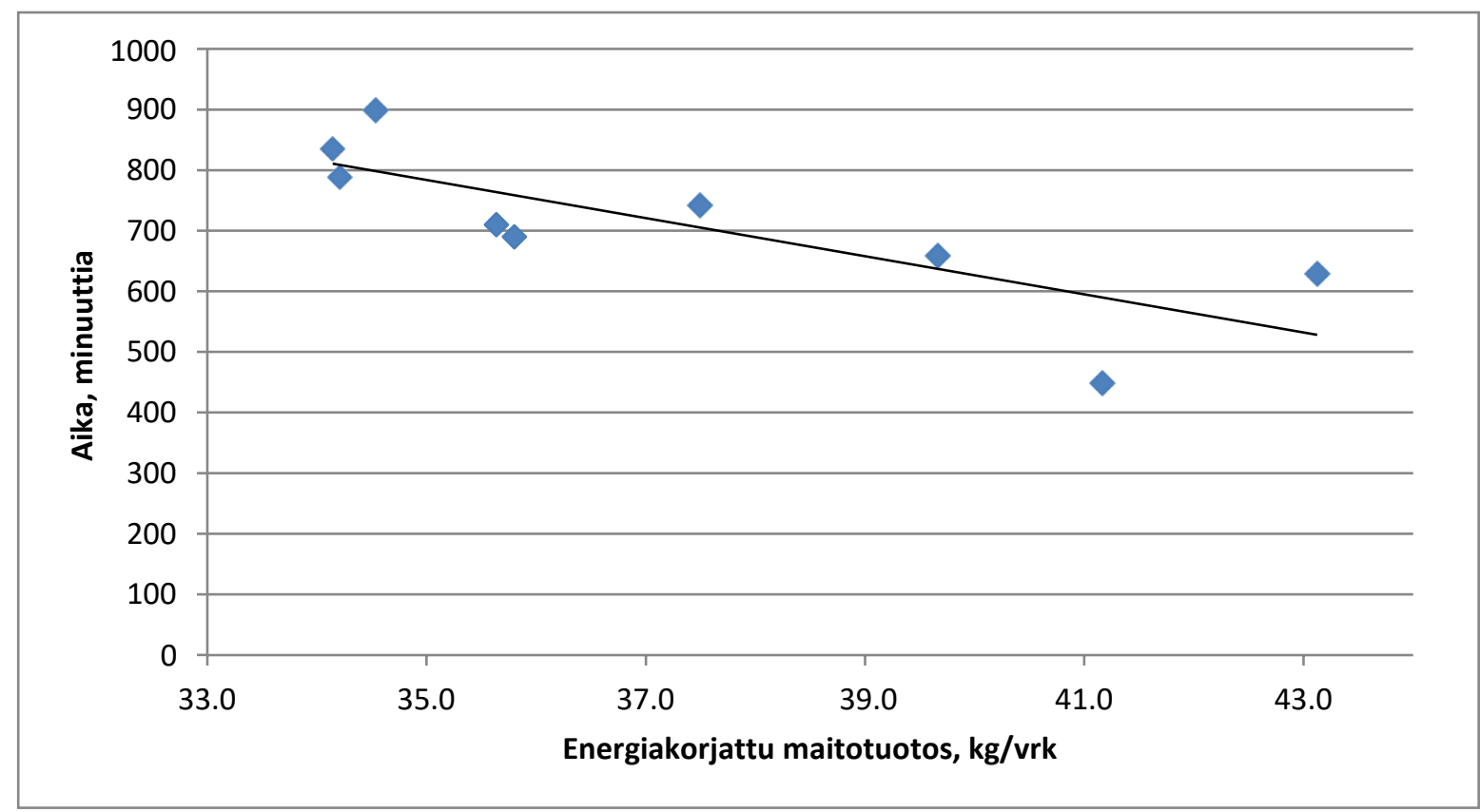

Kuva 4. Lehmien makaamiseen käyttämä aika väheni tuotoksen kasvaessa tilalla A.

\section{Tila B}

Tilalla B lehmien päivätuotokset vaihtelivat 37.1 EKM kg:sta 52.3 EKM kg:aan päivässä. Lehmien makaamiseen käyttämällä ajalla ja tuotostasolla ei ollut yhteyttä. Eniten aikaa makaamiseen käytti vähiten tuottava lehmä ja vähiten aikaa makuulla vietti lehmä B2. Suurituottoisimman lehmän B1 makuuaika vuorokaudessa oli lähes sama kuin lehmän B3. Tilalla B lehmien syöntiin käyttämä aika lisääntyi tuotoksen kasvaessa (Kuva 5). Makuuaika on suhteessa seisoskeluun käytettyyn aikaan, sillä vähiten maannut lehmä B2 käytti eniten aikaa seisoskeluun.

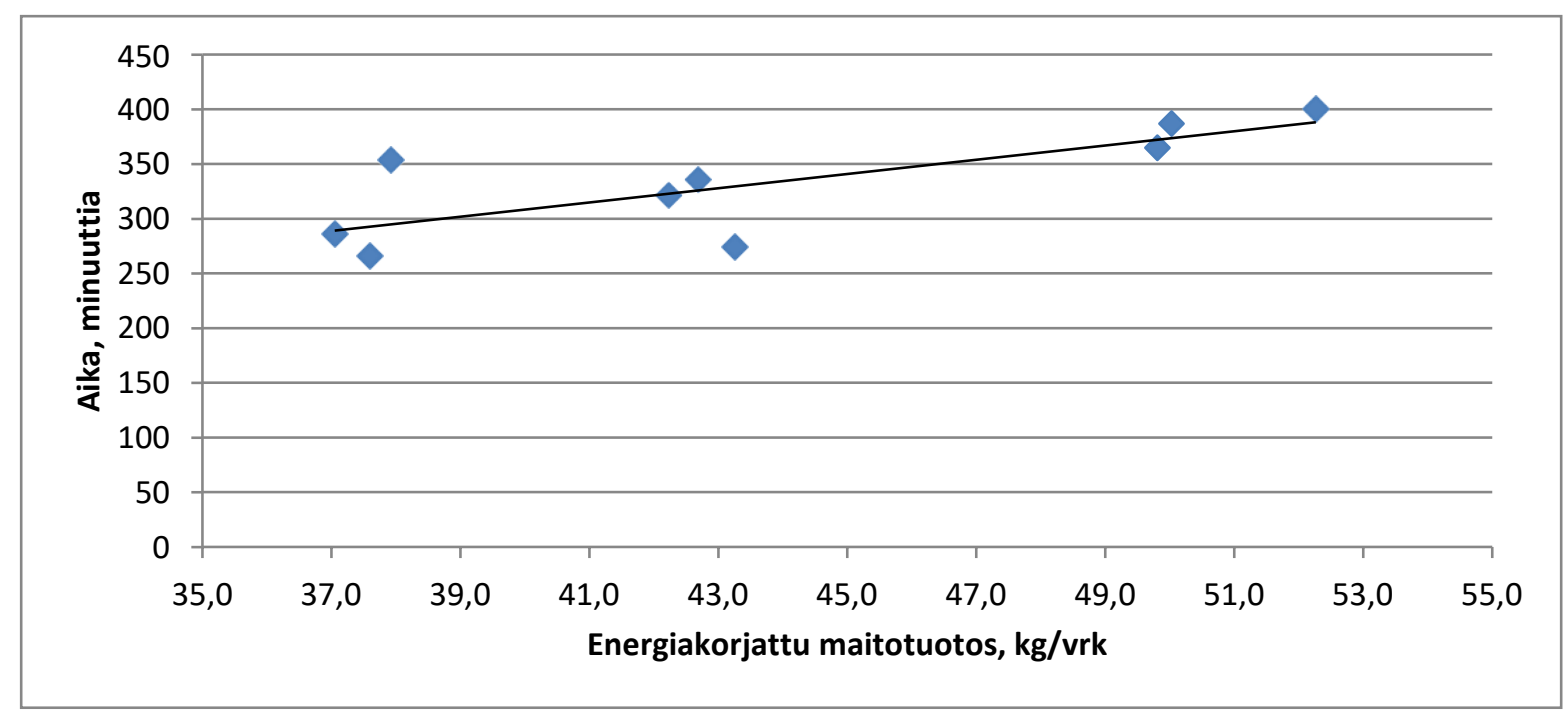

Kuva 5. Lehmien syöntiin käyttämä aika lisääntyi tuotoksen kasvaessa tilalla B.

\section{Johtopäätökset}

Tulosten perusteella voidaan todeta, että tässä tutkimuksessa makuuajan lisääntyminen ei lisännyt maidontuotosta kummallakaan tilalla. Myöskään syöntiajan lisääminen ei suoraa vaikuta tuotosta lisäävästi. Voidaan sanoa, että syöntiajan muutokset kertovat etenkin tilalla A siitä, että syöntiajasta ei ole kovaa kilpailua. Tilalla käytössä oleva automaattinen seosrehuruokinta vähentää kilpailua ruokintapöydällä, jolloin lehmillä on mahdollista leikkiä rehulla. 
Molemmilla tiloilla saatiin viitteitä siitä, että sosiaalinen asema vaikuttaisi tuotokseen. Tilalla A vähiten tuottava lehmä oli hierarkiassa korkeammalla kuin toiset. Tilalla B vähiten tuottavan lehmän korkea asema ei ollut yhtä selkeä. Molemmilla tiloilla arvoasteikossa matalimmalla oleva lehmä tuotti toiseksi eniten maitoa. Tilalla B asema arvoasteikossa haittasi selkeästi lehmän elämää. Tästä kertoo pitkät seisoskeluajat, jotka johtuivat robotille tai parteen odottelusta.

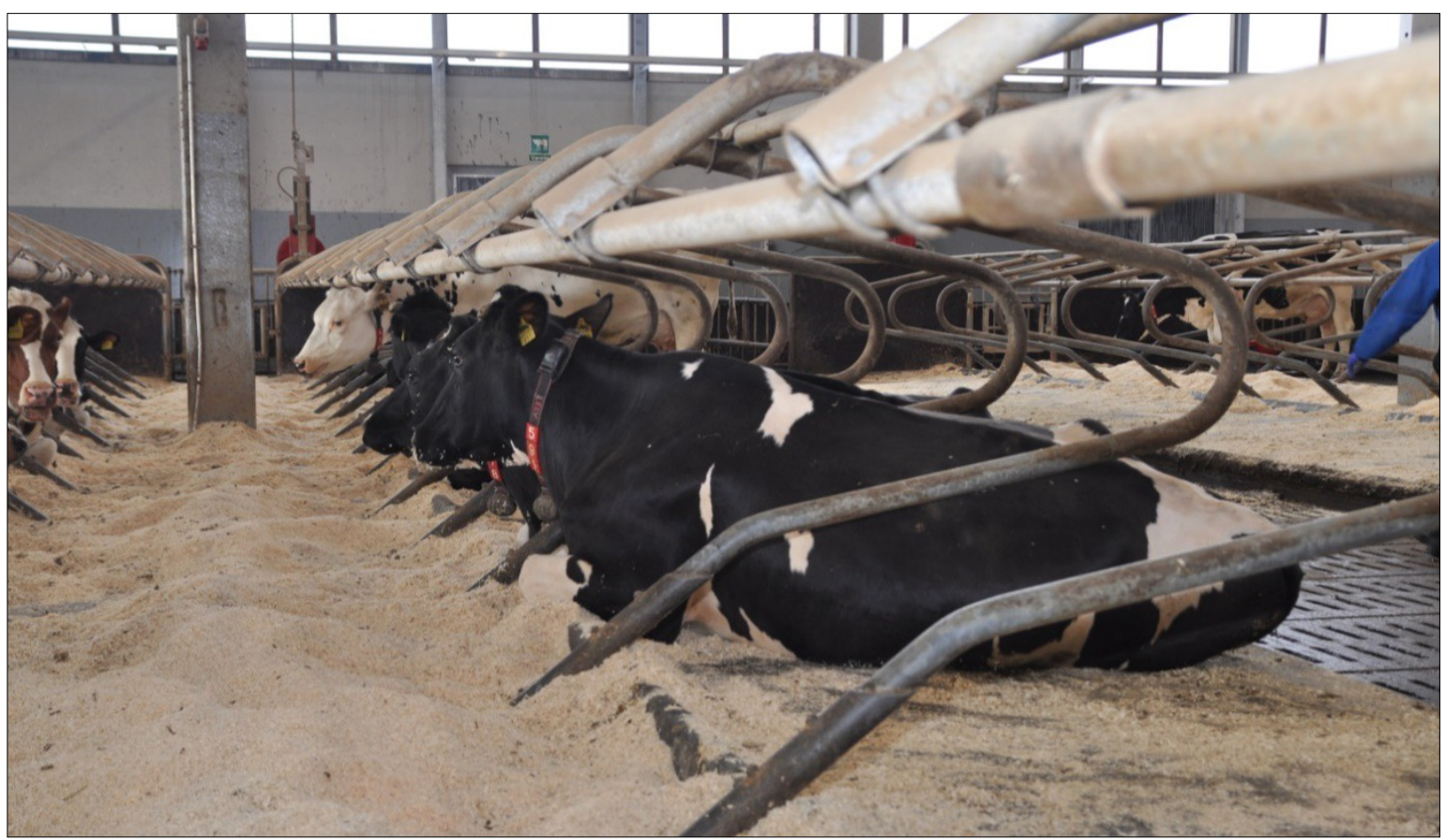

Kuva 6. Tilalla B parren rakenteet antoivat lehmällä runsaasti tilaa nousta ylös ja laskeutua makuulle (Koivisto 2016).

Makuuajan vähentyminen tuotoksen kasvaessa oli joidenkin lähdemateriaalien ja yleisen käsityksen kannalta hieman yllättävä ja syitä on hyvä miettiä. Tilalla A yhteys näkyi selkeästi. Tilalla A parsirakenteet olivat ahtaammat ja parsipedit vanhemmat, jolloin voidaan olettaa, että olosuhteet lehmille eivät olleet yhtä hyvät kuin tilalla B (Kuva 6), jossa lehmien B1 ja B2 makuuajoissa ei ollut juurikaan vaihtelua. Tästä nouseekin kysymys, että onko huonoista olosuhteista ensimmäisenä kärsimässä korkeatuottoiset lehmät, sillä lisääntynyt seisoskelu on rasite jaloille.

\section{Kirjallisuus}

Cook, N. 2016. Time Budgets for Dairy Cows: How Does Cow Comfort Influence Health, Reproduction and Productivity? Retrieved from School of Veterinary Medicine/University of Wisconsin - Madison: https://www.vetmed.wisc.edu/dms/fapm/publicats/proceeds/TimeBudgetsandDairyCowsOmaha.pdf

Deming, J. A., Bergeron, R., Leslie, K. E., \& DeVries, T. J. 2012. Association of housing, management, milking activity, and standing and lying behavior of dairy cows milked in automatic systems. Journal of Dairy Science 96: 344-351.

Grant, R. 2011. Taking Advantage of Natural Behavior Improves Dairy Cow Performance. Retrieved 11. 30. 2015. https://articles.extension.org/pages/11129/taking-advantage-of-natural- behavior-improves-dairy-cowperformance

Helmreich, S., Hauser, R., Jungbluth, T., Wechsler, B., \& Gygax, L. 2014. Time-budget constraints for cows with high milking frequency on farms with automatic milking systems. Livestock Science 167: 315-322.

Hulsen, J. 2014. Lehmä havaintoja: Lehmälähtöisen karjanhoidon opas. Kyntäjä, J. \& Teräväinen, H. (toim.). Vantaa: ProAgria Keskusten Liitto.

Hulsen, J., \& Rodenburg, J. 2010. Building for the cow. Zutphen: Roodbont.

Norring, M., Valros, A., \& Munksgaard, L. 2012. Milk yield affects time budget of dairy cows in tie-stalls.

Journal of Dairy Science 95: 102-108.

Sarjokari, K. 2015. Hyvät olosuhteet. Maito ja Me 2: 44-45.

Winter, A., \& Hillerton, J. E. 1995. Behaviour associated with feeding and milking of early lactation cows housed in an experimental automatic milking system. Applied Animal Behaviour Science 46: 1-15. 